NBER WORKING PAPER SERIES

\title{
THE CHINESE ECONOMIES IN GLOBAL CONTEXT: THE INTEGRATION PROCESS AND ITS DETERMINANTS
}

\author{
Yin-Wong Cheung \\ Menzie D. Chinn \\ Eiji Fujii \\ Working Paper 10047 \\ http://www.nber.org/papers/w10047
NATIONAL BUREAU OF ECONOMIC RESEARCH
1050 Massachusetts Avenue
Cambridge, MA 02138 \\ October 2003
}

We thank Yunjong Wang for comments. The financial support of faculty research funds of the University of California, Santa Cruz is gratefully acknowledged. The views contained herein are solely those of the authors, and do not necessarily represent those of the institutions they are associated with. The views expressed herein are those of the authors and not necessarily those of the National Bureau of Economic Research.

(C2003 by Yin-Wong Cheung, Menzie D. Chinn, and Eiji Fujii. All rights reserved. Short sections of text, not to exceed two paragraphs, may be quoted without explicit permission provided that full credit, including (C) notice, is given to the source. 
The Chinese Economies in Global Context: The Integration Process and Its Determinants Yin-Wong Cheung, Menzie D. Chinn, and Eiji Fujii

NBER Working Paper No. 10047

October 2003

JEL No. F13, F31, F41

\section{ABSTRACT}

The linkages between the People's Republic of China (PRC) and the other Chinese economies of Hong Kong and Taiwan are assessed, and compared against those with Japan and the US. We first characterize the time series behavior of variables corresponding to three criteria of integration, namely real interest parity, uncovered interest parity, and relative purchasing power parity. There is evidence that these parity conditions tend to hold over longer periods between the PRC and all other economies, although they do not hold instantaneously. In general, the magnitude of the deviations from the parity conditions is shrinking over time. Overall, however, Hong Kong exhibits indications of a more advanced level of integration with the PRC. We also find that evidence is surprisingly positive for integration with the US. We then turn to examining the determinants of the degree of integration. Regression results suggest that the degrees of financial and real integration depend upon the extent of capital controls, foreign direct investment linkages, as well as the magnitude of exchange rate volatility.

Yin-Wong Cheung

Department of Economics

SS1

University of California

Santa Cruz, CA 95064

cheung@ucsc.edu

Menzie D. Chinn

Department of Economics

University of Wisconsin

1180 Observatory Drive

Madison, WI 53706-1393

and NBER

mchinn@lafolette.wisc.edu

\section{Eiji Fujii}

Institute of Policy and Planning

University of Tsukuba

1-1-1 Tennodai Tsukuba

Ibaraki, Japan

efujii@sk.tsukaba.ac.jp 


\section{Introduction}

The economies of China - the People's Republic, Hong Kong and Taiwan - constitute one of the most dynamic regions of the world economy, with the People's Republic of China (PRC) registering economic growth over $8 \%$ in 2002. Perhaps of equal significance, the combined output of these three economies is almost twice that of Japan's, and over $60 \%$ that of the US. In addition, their foreign exchange reserves are among the largest in the world. ${ }^{1}$ Yet it is not clear that one can treat the region as an integrated whole; indeed, there has been little systematic examination of whether the links between the PRC and the other two Chinese economies are any stronger than those that connect the PRC to other major economies around the globe, such as Japan or the US.

Over the past two and a half decades, the PRC has been engaged in a process of financial and real integration with the rest of the world. Concurrently, for a variety of geopolitical and economic reasons, the PRC, Hong Kong, and Taiwan - a grouping sometimes termed "Greater China" - have maintained or developed close economic ties. While Hong Kong has a quite long history of economic and financial interactions with the PRC, it might be more surprising to a casual observer that, despite political and ideological differences and occasional tensions, economic links between the PRC and Taiwan have proliferated since the 1990s. According to official statistics, the PRC is the largest recipient of Taiwan's overseas investment and Taiwan is the PRC's third-largest source of foreign direct investment. ${ }^{2}$

These links between the economies comprising "Greater China" need to be placed in context, however. The US and Japan are the PRC's main trading partners and foreign investors. For instance, in 2002 the total trade (imports plus exports) between the PRC and each of the two economies is about US\$100 billion. Foreign direct investment flows to China have also been burgeoning. HK to the PRC flows were nearly US\$17 billion in 2001, while those from Taiwan

1 As of April 2003, the reserves of Hong Kong and Taiwan were, respectively, US\$114.2 and US\$170.6 billion. Those of the People's Republic of China were US\$312.9 billion in February (Economist, May 31-June 6, 2003, p. 98).

$2 \quad$ It is widely believed that the official statistics under-represent the overall Taiwan economic interest in China. For instance, some analysts count Taiwan's total investment in China as just behind that of Hong Kong's but ahead of that of the US. In 2002, electronics companies from Taiwan account for $64 \%$ of the PRC's total information-technology output (The Economist Intelligence Unit, 2003). 
were between US\$3 to US\$4.5 billion. Evidently, linkages of many types have been flourishing between these economies over the last decade or so.

In this paper, we examine some macroeconomic aspects of the PRC's economic integration with Hong Kong, Taiwan, Japan, and the US. Despite its increasing importance in the world economy, there are a relatively limited number of studies of the PRC's interactions with other economies. This is not to say that there has not been any quantitative analysis on the subject. Particularly in the wake of the PRC's accession to the World Trade Organization, quite a few quantitative studies were undertaken. However, most of these focused on sectoral/trade issues. $^{3}$ A thoroughgoing investigation of financial and price linkages is notably lacking. ${ }^{4}$

In addition to assessing the integration between the PRC and the other four economies, the current study examines whether the patterns of integration between the PRC and, on the one hand, the other two Greater China economies and, on the other hand, Japan and the US, are similar. We believe that such an investigation is warranted as there has been much talk of the economic entity called Greater China, comprising the PRC, Hong Kong and Taiwan and is also termed the "China Circle." 5

We use three fundamental parity conditions - real interest parity, uncovered interest parity, and purchasing power parity - to gauge the degree of integration in capital, financial, and goods markets. The real interest parity condition measures the mobility of physical capital, specifically whether capital flows equalize real interest rates across economies. It can be shown that the degree to which real interest rate parity holds depends on the extent to which uncovered interest parity and relative purchasing power parity apply. Since uncovered interest parity involves financial arbitrage between money and foreign exchange markets and relative purchasing power parity entails arbitrage in goods and services, the real interest parity condition embodies elements of both real and financial integration.

3 Recent analyses focused on WTO effects include Wang (2001) and Ma (2001). Other quantitative analyses of trade linkages include Wei and Frankel (1994), Wei et al. (2000), Noland et al. (1998), and Fernald et al. (1999).

$4 \quad$ Ha and Fan (2002) and Shellekens (2002) study the interactions of prices in the PRC and Hong Kong and the deflationary effect on Hong Kong. Cheung, Chinn and Fujii (2003) investigate intra-China linkages.

5 Harding (1995) used the term "Greater China" while Naughton (1997) popularized the title "China Circle". 
In addition to characterizing these linkages, we also document how the strength of each of these links depends on a number of regulatory and economic factors. We investigate, for instance, how much of the gap between real rates of returns depends upon the extent of capital controls, and how much might be due to the uncertainty associated with macroeconomic policies - as summarized by exchange rate and inflation volatility.

The plan of the paper is as follows. In section 2, we lay out a framework for systematically analyzing the components of financial and real integration - corresponding to deviations from uncovered interest parity and relative purchasing power parity. In section 3 , we turn to examining each of these three factors, in terms of their stationarity characteristics, persistence, and trends. The compositions of deviations from the parity conditions are also studied in the same section. Section 4 examines how these deviations can be related to economic factors. Some concluding remarks are offered in Section 5.

\section{Aspects of Capital Market Integration}

There are a number of definitions of capital market integration. Each definition has its own strengths and weaknesses. We will adopt several specific definitions due to Frankel (1991). First, we equate real interest parity with real capital mobility. The real interest parity condition is underpinned by two other conditions: covered interest parity and purchasing power parity. The latter two conditions represent financial capital market integration and goods market integration, respectively.

\subsection{An Accounting Identity}

Consider the ex ante real interest differential between two economies:

$$
r_{t, k}^{e}-r_{t, k}^{* e} \equiv\left(i_{t, k}-\pi_{t, k}^{e}\right)-\left(i_{t, k}^{*}-\pi_{t, k}^{* e}\right)
$$

where $r_{t, k}^{e}$ is the expected k-period real interest rate in the first economy with the "e" and "k" superscripts indicate the variable is expected and the maturity of the debt instrument. The “*” denotes the variables for the second economy. The real interest rate is given by the difference between $i_{t, k}$, the k-period nominal interest rate, and $\pi_{t, k}^{e}$, the expected inflation rate in k-periods. Hence, equation (1) defines the ex ante real rate as the nominal interest rate on an asset of k- 
period maturity, deflated by the inflation rate expected at time $t$ to prevail over the period $t$ to $t+k$ (annualized). ${ }^{6}$ The expected inflation is defined by

$$
\pi_{t, k}^{e} \equiv p_{t, k}^{e}-p_{t} .
$$

where $p_{t, k}^{e}$ and $p_{t}$ are, respectively, the price (in logs) expected to prevail at $\mathrm{t}+\mathrm{k}$ and the price at t. The expected inflation in the second economy is analogously defined by

$$
\pi_{t, k}^{*_{e}} \equiv p_{t, k}^{*_{e}}-p_{t}^{*} \text {. }
$$

The expression for the real interest differential on the right hand side of (1) can be rearranged, and expected depreciation subtracted and added, to yield:

$$
r_{t, k}^{e}-r_{t, k}^{* e} \equiv\left(i_{t, k}-i_{t, k}^{*}-\Delta s_{t, k}^{e}\right)-\left(\pi_{t, k}^{e}-\pi_{t, k}^{e^{*}}-\Delta s_{t, k}^{e}\right)
$$

where expected depreciation is given by:

$$
\Delta s_{t, k}^{e} \equiv s_{t, k}^{e}-s_{t}
$$

and $s_{t}$ is the exchange rate between monies in the two economies expressed in logarithm form. Note that the first term on the right hand side of (4) is the uncovered interest differential, and the second term is the deviation from ex ante relative purchasing power parity. The uncovered interest differential should equal zero when financial capital is perfectly mobile and substitutable; the deviation from purchasing power parity should be zero when goods markets are perfectly integrated.

\subsection{Empirical Implementation}

Strictly speaking, real interest parity is an ex ante concept defined by expectations rather than realized real interest rates. The theoretical relationship between the three parity conditions is defined by identity (4). However, due to the paucity of data on expectations, the identity cannot be used to assess the empirical relevance of these parity conditions. Instead, we employ an operational version based on ex post differentials,

$$
r_{t, k}-r_{t, k}^{*} \equiv\left(i_{t, k}-i_{t, k}^{*}-\Delta s_{t, k}\right)-\left(\pi_{t, k}-\pi_{t, k}^{*}-\Delta s_{t, k}\right)
$$

to examine the data. One way to justify the use of (6) is that, under the rational expectations hypothesis, the ex post realizations are unbiased predictors of the ex ante counterparts. ${ }^{7}$ Since

6 In this case, we are assuming that the interest rates are on highly liquid, money market instruments of identical default risk characteristics. Hence, we do not address default risk premia in our discussion. 
there is substantial evidence that expectations are not unbiased, ${ }^{8}$ we will refer to the term on the left hand side of (6) as the deviation from rational real interest parity, and the two terms on the right hand side as the deviation from rational uncovered interest parity and from rational relative purchasing power parity.

\subsection{Financial versus Real Integration}

Abstracting from the distinction between ex ante and ex post, equations (4) and (6) imply that a sufficient condition for real interest parity to hold is that both uncovered interest parity and relative purchasing power parity hold. While uncovered interest parity pertains to financial integration driven by arbitrage between money and foreign exchange markets - that is, how desirable currencies are viewed and how free money is to move - relative purchasing power parity pertains to how easily goods and services are arbitraged. Hence, real interest parity is a function of both financial and real market integration (Frankel, 1991).

To make this assertion concrete, consider a situation where financial markets in two economies were well integrated, while differential inflation rates were not offset by changes in exchange rates. Then real interest differentials could persist not because financial capital flows were hindered and uncovered interest parity is violated, but because of the breakdown of relative purchasing power parity due to limited strength of the forces that drive together goods prices (expressed in a common currency).

The condition wherein real interest rate parity holds is sometimes termed real capital mobility. That is, real interest rates are equalized when "real" capital is free to move. To see why some observers make this equivalence, consider basic microeconomic theory. An optimizing firm sets the marginal product of capital equal to the user cost of capital. Absent taxes (and ignoring depreciation), the user cost of capital is nominal interest rate, adjusted by the rate of

7 In other words, we are equating the subjective market expectations with the conditional mathematical expectations, viz., $x_{t+k}^{e}=\mathrm{E}\left(x_{t+k} \mid \mathrm{I}_{\mathrm{t}}\right)$, in a steady state such that $x_{t+k}-\mathrm{E}\left(x_{t+k} \mid \mathrm{I}_{\mathrm{t}}\right)=$ $\xi_{t+k}$ where $\xi_{t+k}$ is a true innovation.

See Frankel and Froot (1987) and Chinn and Frankel (1994). 
inflation of its output. Hence real interest parity is taken as a signal of the equalization of the marginal product of capital across countries. ${ }^{9}$

\section{Empirical Results}

The data considered in this exercise are monthly observations on one-month interbank interest rates, exchange rates, and consumer price indexes for the PRC, Hong Kong, Taiwan, Japan, and the US, from February 1996 to June 2002. See the Data Appendix for a more detailed description. The period of analysis is dictated by data availability and, more importantly, by the realities of the liberalization process in the PRC. A unified national interbank market was only established in January of 1996; prior to that the interbank market was substantially controlled (Xie, 2002). Hence, extending the interest rate series backwards would not yield more information relevant to assessing international financial integration. ${ }^{10}$

For each pair of economies, the ex post real interest differential $\left(r_{t, k}-r_{t, k}^{*}\right)$, ex post uncovered interest differential $\left(i_{t, k}-i_{t, k}^{*}-\Delta s_{t, k}\right)$, and ex post relative purchasing power differential $\left(\pi_{t, k}-\pi_{t, k}^{*}-\Delta s_{t, k}\right)$ are constructed to examine the relevance of the parity conditions and infer the degree of integration between the PRC and other economies. For notational simplicity, we drop the term "ex post" hereafter.

Table 1 presents the summary descriptive statistics. Several observations are in order. First, for the real interest differential, the Hong Kong/PRC series has the smallest mean (in absolute value), but not smallest range (maximum - minimum), nor smallest variance. If these numbers are used to assess integration, then Hong Kong and the PRC appear to have a high level of integration. $^{11}$

However, recall that the deviations from real interest parity are a composite of other deviations. When focusing solely on the financial side, the deviation from uncovered interest

$9 \quad$ There is a subtlety involved in using parity conditions to evaluate the level of integration. When a parity condition is rejected, then enlargements and diminutions of deviations may be due either to greater economic integration, greater convergence of economic policies, or both. 10 There is a separate question of whether the one-month rate is representative of other short-term interest rates, including the commercial paper and repo rates. Li and Peng (2002) argue that in recent years the segmentation between these short-term instruments has largely disappeared.

11 In the presence of a 1997 dummy variable, the Taiwan/PRC pair, instead of the Hong Kong/PRC pair, has the smallest absolute average real interest differential. 
parity tells a different story. The Hong Kong/PRC and US/PRC pairs appear the most tightly linked, with the smallest absolute mean values and smallest ranges. The Japan/PRC pair yields the largest absolute value of the mean differential deviation. This result is likely driven by the exchange rate arrangements adopted by the PRC. During the sample period, currencies of the PRC and Hong Kong are effectively pegged to the US dollar and, thus, the exchange rate has a limited effect on the uncovered interest deviations. On the other hand, the Japan/PRC pair is characterized by large and volatile exchange rate variation and thus large deviations from rational uncovered interest parity.

The deviations from purchasing power parity are generally fairly small in their mean values with the exception of the Japan/PRC link. The range is smallest for the Hong Kong/PRC and US/PRC pairs, cases where the exchange rates are pegged. Again, the results confirm that the choice of exchange rate regime has major import for the magnitude of the dis-parity.

The three differential series are graphed for each of the PRC pairs in Figures 1 to 4. Taking the scale of these graphs into consideration, the three differential series of the four PRC pairs display two distinct patterns. Figures 1 and 3 indicate that the real interest differentials of the Hong Kong/PRC and US/PRC pairs are greatly influenced by the deviations from the relative purchasing power parity. On the other hand, the uncovered interest differentials and deviations from relative purchasing power parity for the Japan/PRC and Taiwan/PRC pairs tend to offset each other and result in a relatively small real interest differential. These observations corroborate the numbers reported in Table 1 - the averages of the Japan/PRC and Taiwan/PRC real interest differentials are considerably smaller than those of the other two differential series.

In the following subsections, we provide some formal evaluations of the parity conditions via several perspectives. First, we test for the presence of a unit root in these differential series. Second, we gauge the predictive ability of the past values of a differential series. Third, we assess whether the deviations from parity conditions are shrinking over time or not. Fourth, we examine the composition of the volatilities of the three differential series.

\subsection{Real Interest Parity}

In some earlier studies, regression methods are used to determine the validity of real interest parity (Cumby and Obsfeld, 1984). For example, interest rate differentials are regressed on inflation differentials and the coefficient estimates are used to assess whether the real interest 
rate parity condition holds. ${ }^{12}$ In this study, we use the concept of mean stationarity to evaluate the parity condition. If the deviations from real interest parity are stationary, then even though the condition does not hold in the short run, it holds in the long run because deviations from parity are transitory. The argument follows from the property of a stationary time series; a stationary series will revert back to its equilibrium value after being disturbed by external shocks. On the other hand, if the deviations from parity are not stationary, shocks can lead to permanent displacements from equilibrium and there is no built-in mechanism to restore the parity condition even in the long run. ${ }^{13}$ The use of the stationarity criterion is appropriate because a parity relation is usually established under some ideal conditions that are unlikely to hold in the short run. The stationarity criterion can also be rationalized by recalling that we only observe ex post inflation and depreciation rates; hence it makes no sense to assume that the ex post parity conditions hold instantaneously. As long as the parity conditions hold ex ante and the expectations errors are mean stationary, tests for stationarity will be informative.

A modified Dickey-Fuller test known as the ADF-GLS test (Elliott, Rothenberg, Stock, 1996) is used to test for stationarity. While the standard Dickey-Fuller procedure is notorious for its low power, the ADF-GLS test is shown to be approximately uniformly most powerful invariant. Consider a series $\left\{q_{t}\right\} ; q_{t}=$ real interest differential, uncovered interest differential, and relative purchasing power differential at time t. The ADF-GLS ${ }^{\tau}$ test that allows for a linear time trend is based on the following regression:

$$
(1-L) q_{t}^{\tau}=\alpha_{0} q_{t-1}^{\tau}+\sum_{k=1}^{p} \alpha_{k}(1-L) q_{t-k}^{\tau}+\varepsilon_{t}
$$

where $q_{t}^{\tau}$ is the locally detrended process under the local alternative of $\bar{\alpha}$ and is given by

$$
q_{t}^{\tau}=q_{t}-\widetilde{\gamma}^{\prime} z_{t}
$$

12 There is an extensive literature on testing real interest parity. See Mishkin (1984), Mark (1985), and Cumby and Mishkin (1986). In some studies, exact formula for calculating interest rate variables (instead of log approximations) are typically used in the context of testing for real interest parity. However, it is noted that data derived from exact formulae and log approximations gave qualitatively similar test results. Following the general practice, the test results in Tables 2 to 5 are based on the log approximation.

13 The constant associated with the real interest parity deviation can be interpreted as a time-invariant difference in the default risk or liquidity attributes of the money market instruments that have been assumed away in the algebraic expressions. 
with $z_{t}=(1, t)^{\prime} . \tilde{\gamma}$ is the least squares regression coefficient of $\widetilde{q}_{t}$ on $\widetilde{z}_{t}$, where $\left(\widetilde{q}_{1}, \widetilde{q}_{2} \ldots . . . \widetilde{q}_{T}\right)=$ $\left(q_{1},(1-\bar{\alpha} L) q_{2}, \ldots,(1-\bar{\alpha} L) q_{T}\right),\left(\widetilde{z}_{1}, \widetilde{z}_{2} \ldots \ldots \widetilde{z}_{T}\right)=\left(z_{1},(1-\bar{\alpha} L) z_{2}, \ldots,(1-\bar{\alpha} L) z_{T}\right)$, and $L$ is the lag operator. The local alternative $\bar{\alpha}$ is defined by $\bar{\alpha}=1+\bar{c} / \mathrm{T}$ for which $\bar{c}$ is set to -13.5 . The ADF-GLS ${ }^{\mu}$ test, which allows for only an intercept, involves the same procedure as the ADF-GLS ${ }^{\tau}$ test, except that $q_{t}^{\tau}$ is replaced by the locally demeaned series $q_{t}^{\mu}$, which is obtained by setting $z_{t}=1$ and $\bar{c}$ to -7 . In implementing the test, the lag parameter $\mathrm{p}$ is chosen to make the error term $\varepsilon_{t}$ a white noise process. The unit root hypothesis is rejected when the ADF-GLS test statistic, which is given by the usual $t$-statistic for $\alpha_{0}=0$ against the alternative of $\alpha_{0}<0$, is significant. See Elliott, Rothenberg, Stock (1996) for a detailed description of the testing procedure.

The results of applying the ADF-GLS ${ }^{\tau}$ and ADF-GLS ${ }^{\mu}$ tests to the four real interest differential series are presented in Panel A of Table 2. For all the three series, the residual Qstatistics indicate that the selected lag specifications are quite adequate. Both the ADF-GLS ${ }^{\tau}$ and $\mathrm{ADF}-G L S^{\mu}$ test statistics are negative and significant; suggesting that the real interest differential series are stationary. That is the deviations from real interest parity are stationary and tend to converge over time.

Panel B of Table 2 reports the results of the following regression:

$$
q_{t}=\alpha_{0}+\sum_{k=1}^{p} \alpha_{k} q_{t-k}+\varepsilon_{t}
$$

This regression is used in some previous studies assessing the parity condition. Under instantaneous real interest parity, the expected real interest differential is random, has a zero mean, and cannot be predicted by available information. Thus, the significance of $\alpha_{k}$ 's in (9) is considered as evidence against the validity of the (instantaneous) parity condition.

As reported in Panel B, all the four PRC real interest differential series display significant persistence. Deviations from the real interest parity are predictable and the markets are not efficient in this sense. Thus, the results indicate that the PRC is imperfectly integrated with the other economies - a finding that is not surprising because the PRC has strict controls on both trade and financial flows. Nonetheless, despite the limited extent of integration and the failure of short-run real interest parity, the stationarity results in Panel A suggest that the real interest rates 
of PRC and all other economies are linked in the long run and they do not drift apart without a bound over time.

The explained components of these differential series, as indicated by the adjusted- $\mathrm{R}^{2}$, range from $4.5 \%$ of the US/PRC real interest differentials to $19.2 \%$ of the Taiwan/PRC differentials. The adjusted- $\mathrm{R}^{2}$ s from the Hong Kong/PRC and Taiwan/PRC regressions are larger than those from the other two pairs. Apparently, the real interest differentials between the Greater China economies are more predictable than those between the PRC and the two nonChinese economies.

Next, we use a simple panel setting to reveal the possible trending behavior of dis-parity. Specifically, we would like to investigate whether the magnitude of deviation is declining during the sample period. To this end, we construct an annual measure of absolute deviation by averaging the monthly absolute real interest differentials. Specifically, we calculate:

$$
\widetilde{q}_{j, t}=12^{-1} \sum_{k=1}^{12} \operatorname{abs}\left(q_{j, t, k}\right)
$$

where $\operatorname{abs}\left(q_{j, t, k}\right)$ is the absolute value of the real interest rate differential between economy $\mathrm{j}$ and the PRC in the k-th month during year $\mathrm{t}, \mathrm{j}=$ Hong Kong, Japan, Taiwan, and the US, and $\mathrm{t}=$ $1996, \ldots, 2001 .^{14} \mathrm{We}$ then estimate a common trend in the obtained average absolute deviations by running a panel regression:

$$
\widetilde{q}_{j, t}=\alpha_{j}+\beta t+\varepsilon_{j, t}
$$

and report the results in Table 2, Panel C. The economy-specific intercept term $\alpha_{j}$ allows individual absolute deviation series to have different means. The estimated common trend term reported in the row labeled "Common" is statistically significant and negative, suggesting that the magnitude of real interest rate differentials is, in general, shrinking over time.

It is useful to identify which economy is the major source of the general decline in the absolute deviation from real interest parity. For this reason, we estimate trend coefficients between the PRC and 1) the other Greater China economies, 2) Japan and the US, and 3) individually economies. The results are reported in the row labeled "Group' and "Individual." All these trend coefficient estimates are negative - indicating that the PRC real interest rate gap tends to dwindle over time vis-à-vis other economies. The most notable decline is between the PRC and Japan, as manifested by both the size and the statistical significance of the trend

\footnotetext{
14 The year 2002 is excluded because we have only 6 observations for that year.
} 
coefficient estimate. In sum, there is evidence that the PRC is increasingly linked with the other major economies. This finding is robust to the inclusion of a dummy for the 1997 currency crisis. ${ }^{15}$

\subsection{Uncovered Interest Parity}

The real interest parity condition incorporates aspects of both financial and real integration. Although the results in the previous subsection are supportive of long-run real interest parity, it is instructive to isolate the sources of rejection of short-run integration. To this end, we examine the cases of financial and real integration individually. The results related to financial integration are given in Table 3, in a format analogous to that used in Table 2.

Panel A presents the results of applying the unit root tests on the uncovered interest differential series. For all pairs, excepting the US/PRC, the unit root hypothesis is strongly rejected by both ADF-GLS ${ }^{\tau}$ and ADF-GLS ${ }^{\mu}$ test statistics. When a dummy variable for the 1997 crisis is included, the US/PRC series exhibits stationarity. ${ }^{16}$ Thus, after accounting for the 1997 crisis, all the uncovered interest differential series are stationary and shocks to uncovered interest parity are transitory.

The results of fitting the uncovered interest differential to equation (9) are given in Panel B. The deviation from uncovered interest parity does not appear random for the Hong Kong/PRC and US/PRC pairs - the lagged uncovered interest differential variables are positively significant and indicative of strong persistence. The adjusted- $\mathrm{R}^{2} \mathrm{~s}$ are quite high at $62 \%$ and $83 \%$, respectively. If monies are free to move across markets, arbitrage can generate profits based on the pattern of persistent deviation and help restore the parity. However, this kind of arbitrage activity is quite difficult, especially in the short run, given the prevailing capital controls in the PRC.

The Japan/PRC and Taiwan/PRC pairs display a different pattern. The lagged differentials are small and insignificant - indicating the deviations are quite random.

15 The sensitivity to the 1997 dummy is investigated for all results reported in the tables. The reported results are quite robust to the inclusion of the dummy variable. To conserve space, the results allowing for the dummy are discussed only when they are different from those in the tables.

16 The results for US/PRC pair with the 1997 dummy are 1) ADF-GLS ${ }^{\mu}=-2.869^{*}$ [1], $\mathrm{Q}(6)=7.792$, and $\mathrm{Q}(12)=18.096$, and 2) $\mathrm{ADF}-\mathrm{GLS}^{\tau}=-3.335^{*}[1], \mathrm{Q}(6)=6.596$ and $\mathrm{Q}(12)=$ 17.158 . 
Interestingly, these two differentials series have a variance that is 50 times to 125 times larger than those of the Hong Kong/PRC and US/PRC series. ${ }^{17}$ The unduly high volatility may make it difficult to uncover significant coefficients in the Japan/PRC and Taiwan/PRC regressions.

The annual absolute deviation from uncovered interest parity, which is constructed in the same manner as the absolute deviation from real interest parity (see equation (10)), is used to assess the trending behavior of uncovered interest dis-parity. While all the estimated common, group, and individual time trends have a negative sign - indicating the differentials are narrowing during the sample - only the estimates for the Hong Kong/PRC and US/PRC pairs are statistically significant. Again, the insignificant results are associated with the highly variable Japan/PRC and Taiwan/PRC series.

\subsection{Relative Purchasing Power Parity}

The relative purchasing power differential series are used to assess goods market integration. The notion of relative purchasing power parity in (4) is different from the purchasing power parity commonly examined in the literature. The relative purchasing power parity that constitutes the equivalence of parities is akin to the Roll's (1979) efficient market purchasing power parity. Roll (1979) shows that, under the efficient market assumption, ex ante deviations from purchasing power parity are unpredictable. Frankel (1991), for example, suggests that violation of ex ante relative purchasing power parity is associated with incomplete integration of goods markets.

The empirical results are presented in Table 4. The ADF-GLS ${ }^{\tau}$ and ADF-GLS ${ }^{\mu}$ tests strongly reject the presence of a unit root in these differential series. While the stationarity result is expected from the parity identity relationship and the results in the previous two subsections, it is reassuring to see the actual relative purchasing power differential series are stationary. Thus, there is evidence of long-run goods market integration between the PRC and other economies.

The results in Panel B are quite different from the corresponding panels in the two preceding tables. The coefficient estimates of the lagged deviation from relative purchasing power parity are small and insignificant and the adjusted- $\mathrm{R}^{2} \mathrm{~s}$ are quite close to zero. If the

17 During the sample period, Hong Kong and PRC have their currencies effectively pegged to the US dollar. Thus, the Hong Kong/PRC and US/PRC exchange rates are relatively stable and contribute little to the related uncovered interest differentials. On the other hand, the exchange rates of Taiwan and Japan vis-à-vis PRC are more volatile. 
information set is restricted to lagged relative purchasing power parity deviations, $\left(\pi_{t, k}-\pi_{t, k}^{*}-\Delta s_{t, k}\right)$ is a random series. The result is supportive of the Roll's (1979) efficient market purchasing power parity, which postulates $\left\{\pi_{t, k}^{e}-\pi_{t, k}^{e^{*}}-\Delta s_{t, k}^{e}\right\}$ is a zero mean random series.

There is no evidence of a decrease in the magnitude of relative purchasing power deviations revealed in Panel $\mathrm{C}$ of Table 4. The results are based on fitting the annual averages of absolute differentials to equation (11). All three types of time trend; common, group, and individual, are not significant. Again, the results are in contrast with the corresponding ones in Tables 2 and 3, which find substantial evidence of diminishing deviation from the two interest parities. Note, however, that the PRC opened its goods and services markets, albeit in a gradual fashion, long before launching financial reforms in the late 1990s. It is possible that the magnitude of relative purchasing power deviations declined before the current sample period and, hence, does not manifest itself in a declining trend in recent years.

To investigate the possibility that most of the process of goods market integration occurred before 1996, we extended the sample back to January 1984. This data span includes the longest available exchange rate and price series. For the extended sample, the common trend estimate is -0.291 (standard error $=1.122$ ), the time trend estimate of the Hong Kong/PRC and Taiwan/PRC group is -0.722 (standard error $=0.220$ ), and the one of the Japan/PRC and US/PRC group is 0.138 (standard error $=2.257$ ). For the individual time trends, only the Hong $\mathrm{Kong} / \mathrm{PRC}$ one is statistically significant; the estimate is -1.037 with standard error equals to 0.264. Thus, only the time trend estimates involving Hong Kong are significant and negative, indicating it is only the relative purchasing power parity gap between the PRC and Hong Kong that is declining during the period under investigation. The result is consistent with the fact that, among the four economies under consideration, Hong Kong has the most long-standing "preferential" political and economic links with the PRC, making that economy better positioned to integrate with the PRC. Overall, the results pertaining to the longer sample and those in Table 4 suggest that there is considerable evidence of goods market integration between the PRC and Hong Kong, and that much of it took place in the period before 1996.

The results of testing the parity conditions are summarized in Table 5. All in all, there is evidence that the three parity conditions hold in the long run. The unit root null is rejected for all the series and, thus, the deviations from these parity conditions are stationary. Given the short 
sample considered and the usual concern about the power of unit root tests, the evidence in favor of the three long-run parity conditions is quite strong (even if these conditions do not necessarily hold in the short run). There is also some evidence that some economy-pairs experience a decline in the magnitude of deviations.

Apparently, the PRC and Hong Kong have the highest level of integration. This finding is not too surprising given the development of close ties that preceded the PRC's more recent set of economic reforms. On the other hand, Taiwan, compared with Japan and the US, does not appear to be more integrated with the PRC. Thus, the integration between the Greater China economies is not uniformly deeper than that between the PRC and the other major economies.

\subsection{The Composition of Deviations from Parity Conditions}

The variance of a differential series provides a measure of the extent of deviation from a parity condition. For example, consider real interest parity. If the parity condition holds instantaneously, then the real interest differential series will be identically equal to zero. If the parity is subject to large shocks, then the variance of the differential series is large. Thus, a large differential variance is indicative of substantial deviation from the parity condition. There are two caveats. The first is that the ex post deviations impound an expectational error, so larger deviations can be an indication of increased uncertainty. Second, even a constant deviation from the parity yields a zero variance. Due to impediments to capital flows including formal barriers and transaction costs, the parity condition may not hold exactly in reality. The impediments can create a zone in which it is not feasible for arbitrage to restore the parity. Under such circumstances, the observed differential series does not have a zero mean and its variance can be interpreted as a measure of deviation from parity allowing for the effect of impediments to capital flows.

The variance of differential series offers a direct way to assess the components of disparity. The variance of real interest differentials can be equivalently written as

$$
\begin{aligned}
\operatorname{Var}\left(r_{t, k}-r_{t, k}^{*}\right) \equiv & \operatorname{Var}\left(i_{t, k}-i_{t, k}^{*}-\Delta s_{t, k}\right)+\operatorname{Var}\left(\pi_{t, k}-\pi_{t, k}^{*}-\Delta s_{t, k}\right) \\
& -2 \operatorname{Cov}\left(i_{t, k}-i_{t, k}^{*}-\Delta s_{t, k}, \pi_{t, k}-\pi_{t, k}^{*}-\Delta s_{t, k}\right) .
\end{aligned}
$$

The intensity of deviations from real interest parity depends on the extents of financial and goods market dis-integration and the comovement between deviations from uncovered interest parity 
and relative purchasing power parity. The decomposition of $\operatorname{Var}\left(r_{t, k}-r_{t, k}^{*}\right)$ using actual data can pinpoint whether it is the barriers in financial markets or in goods markets that cause the failure to equalize real interest rates.

By the same token, the variances of uncovered interest and relative purchasing power differentials can be expressed as

$$
\operatorname{Var}\left(i_{t, k}-i_{t, k}^{*}-\Delta s_{t, k}\right) \equiv \operatorname{Var}\left(i_{t, k}-i_{t, k}^{*}\right)+\operatorname{Var}\left(\Delta s_{t, k}\right)-2 \operatorname{Cov}\left(i_{t, k}-i_{t, k}^{*}, \Delta s_{t, k}\right)
$$

and

$$
\operatorname{Var}\left(\pi_{t, k}-\pi_{t, k}^{*}-\Delta s_{t, k}\right) \equiv \operatorname{Var}\left(\pi_{t, k}-\pi_{t, k}^{*}\right)+\operatorname{Var}\left(\Delta s_{t, k}\right)-2 \operatorname{Cov}\left(\pi_{t, k}-\pi_{t, k}^{*}, \Delta s_{t, k}\right)
$$

Equations (12), (13) and (14) allow us to assess the roles of nominal interest rates, exchange rate changes, relative inflation rates, and their comovements on deviations from the parities.

The decomposition results based on (12), (13), and (14) are presented in Table 6. For real interest differentials the Japan/PRC pair has the smallest variance while the Taiwan/PRC pair has the largest one. The relative contributions of uncovered interest dis-parity and relative purchasing power dis-parity are different across these economy-pairs. The Hong Kong/PRC and US/PRC pairs are similar - the variances of uncovered interest and relative purchasing power differentials are smaller than that of real interest differentials. In the case of Hong Kong/PRC, $66.7 \%$ of the variation is attributable to relative purchasing power variability and $16.7 \%$ to uncovered interest variability. For the US/PRC real interest differential variance, slightly more than $90 \%$ is attributable to relative purchasing power parity variability and $34 \%$ to uncovered interest variability.

In contrast, the variances of the Japan/PRC and Taiwan/PRC real interest differentials are much smaller than those of their components. Specifically, the variances of uncovered interest and relative purchasing power differentials are at least 40 times larger than the variance of real interest difference for Japan/PRC and at least 6 times for Taiwan/PRC. A negative comovement between its two components keeps the variances of real interest differentials of Japan and Taiwan in the same order of magnitude as those obtaining for the Hong Kong and the US links. That is, individually, the real interest and relative purchasing power disequilibria between the PRC, Japan, and Taiwan are large, but they tend to offset each other (though not perfectly) and result relatively small deviations in the real interest market. ${ }^{18}$

18 The results echo the differential series graphed in Figures 2 and 4. 
The decomposition results for uncovered interest and relative purchasing power differentials can be summarized quite simply. The variances of the Japan/PRC and Taiwan/PRC pairs are higher than those of the Hong Kong/PRC and US/PRC pairs. For the two former cases, exchange rate variation is the main contribution to variability while, for the latter two cases, relative price and relative interest variations are the main determinants.

The pattern of results reflects the exchange rate arrangements of these economies. As already noted, both Hong Kong and the PRC effectively pegged their currencies to the US dollar during the sample; hence the Chinese exchange rate regimes relative to the US and to Hong Kong are de facto pegs. In contrast, Taiwan and Japan are best characterized as following a policy of managed floating. When exchange rates are floating, exchange rate variability accounts for almost the entire variability of the deviations from parity. The situation is exactly reversed when the exchange rate is pegged. Thus, the exchange rate arrangement has significant implications for using these parity conditions as a measure of integration.

\section{The Economic Determinants of Parity Deviations}

To this point, we have discussed the time series behavior of deviations from these three parity conditions. One drawback of the pure time series approach is that we are unable to determine whether the decline in the size of the differentials (when it occurs) is due to increasing integration, or due to convergence in macroeconomic policies. For instance, if uncovered interest parity does not hold perfectly, then in principle, monetary policies can exert an influence on the ex ante and ex post deviation from uncovered interest parity. ${ }^{19}$

\subsection{A Regression Equation}

In order to ascertain whether deviations from parity conditions are a function of the reduction in trade barriers and financial restrictions, we undertake a panel regression analysis. We posit that financial account restrictions will impede capital flows, thereby allowing greater scope for deviations from uncovered interest parity. To approximate the degree of financial account restrictions, we employ the capital control index compiled by Chan-Lee (2002) for the Asian Development Bank. The index is denoted by $K_{A O P E N_{j, t}}-$ a large index value means a low level of capital controls.

19 See for instance Willett, Keil and Ahn (2002). 
Similarly, we anticipate greater trade barriers would be correlated with greater deviations from purchasing power parity. Unfortunately, we do not possess good information on the extent of trade barriers. Many of the existing estimates pertain to points in time. Consequently, we use trade intensity as a proxy for the amount of arbitrage activity and assume it is negatively related to trade barriers. More specifically, we adopt:

$$
T R A D E_{j, t}=\left(X_{P R C, j, t}+M_{P R C, j, t}\right) /\left(X_{j, t}+M_{j, t}+X_{P R C, t}+M_{P R C, t}\right)
$$

where $X_{P R C, j, t}\left(M_{P R C, j, t}\right)$ is the PRC's exports to (imports from) economy j, $X_{j, t}\left(M_{j, t}\right)$ is j's total exports (imports), and $X_{P R C, t}\left(M_{P R C, t}\right)$ is the PRC's total exports (imports), all at time t. ${ }^{20}$

The factor endowment theory of international trade suggests that convergence of product prices across economies; either free movement of goods or that of production factors can enhance, for example, goods market integration. Thus, foreign direct investment (FDI) that induces factor movements can affect the parity condition. ${ }^{21}$ For this reason, we include FDI in the exercise and, specifically, anticipate that a strong FDI link leads to a small relative purchasing power deviation. The variable $F D I_{j, t}-$ the economy j's FDI flow to the PRC in period t normalized by the PRC's gross domestic product is used to measure the FDI effect.

Two other variables reflect the conduct of macroeconomic policies. The first is the volatility of ex post exchange rate changes; the second the volatility of relative inflation. The definitions of the differential series offer a clue to the effect of exchange rate movements. Exchange rates are notoriously difficult to forecast. A priori, one would expect that greater deviations from ex post uncovered interest parity occur with greater exchange rate volatility. One possibility is that high ex post exchange rate volatility occurs with large expectation errors, which affect ex post uncovered interest parity deviations. Also, exchange rate volatility can influence relative purchasing power parity deviations - exchange rate volatility coupled with sticky prices are deemed to be a reason why the purchasing power parity does not hold.

Inflation is not easy to predict and at the same time affects nominal interest rates. We hypothesize the relative inflation variability can influence uncovered interest differentials via the

20 The measure has been used in empirical studies of the gravity models of international trade. See for instance Frankel and Rose (1998).

21 In other words, FDI is considered as a substitute for goods trade and, hence, induces relative price convergence between economies. See, for example, Goldberg and Klein (1998, 1999) for empirical evidence. 
nominal interest differential and relative purchasing power parity deviations via the relative inflation term. We use 13-month centered moving variances as proxies of the volatilities of exchange rate changes and relative inflation. The proxies are denoted by $M V S_{j, t}$ and $M V P_{j, t}$, respectively.

For each of three differential series, we pool the data across the four economy-pairs and estimate

$$
\begin{aligned}
A D E V_{j, t} & =c+\delta_{1} K_{A O P E N_{j, t}}+\delta_{2} \ln T R A D E_{j, t}+\delta_{3} \ln F D I_{j . t} \\
& +\delta_{4} M V S_{j, t}+\delta_{5} M V P_{j, t}+u_{j, t}
\end{aligned}
$$

where $A D E V_{j, t}$ is the absolute deviation from a given parity, $c$ is a constant, $u_{j, t}$ is the disturbance term, and the other variables are proxy variables described above.

\subsection{Empirical Results}

The estimation results are summarized in Table 7. The selected economic variables explain absolute uncovered interest and relative purchasing power parity differentials quite well but not absolute real interest differentials. These variables account for only $2.4 \%$ of absolute real interest differential variation but over $30 \%$ of variations in the other two series. Indeed, none of the economic variables is significant in the absolute real interest differential regression.

The capital control index $K A O P E N_{j, t}$ has the expected negative effect on all three absolute differential series. However, only the two coefficients from the absolute uncovered interest and relative purchasing power parity differential equations are statistically significant. Although slightly counterintuitive, it is not too surprising to observe a significant capital control effect on deviations from relative purchasing power parity since capital controls usually accompany trade impediments. The regression results confirm that a low level of capital controls facilitates integration. ${ }^{22}$

The effect of the trade variable $T R A D E_{j, t}$ is difficult to interpret. Specifically, this variable has an unexpected positive effect on the three differential series. While the trade variable is insignificant in two series, it is significant for absolute relative purchasing power

22 Note that statistical significance is evaluated using robust standard errors. The least absolute deviation (LAD) approach was also used to assess the capital control effect. Under LAD, KAOPEN has a significant negative effect on absolute real interest differentials though there was no improvement in the adjusted R-squared. 
parity differentials. We do not have an explanation for the results. Other measures of trade intensity were also explored but did not change the results. Nonetheless, it is noted that in studying the effect of trade on purchasing power parity deviations, Campa and Wolf (1997) also find a similar trade variable to have a positive effect on parity differentials. In our context, the trade variable may not be a good proxy for (the absence) of trade barriers.

The effects of the FDI and exchange rate volatility variables, $F D I_{j, t}$ and $M V S_{j, t}$, are significant and with the expected signs for absolute uncovered interest and absolute relative purchasing power parity differentials but are statistically insignificant for absolute real interest differentials. The significant FDI effect is negative; indicating small dis-parity is associated with a high level of FDI. FDI flows facilitate movements of financial and physical capitals and, thus, narrow gaps in uncovered interest and relative purchasing power parities. On the other hand, the significant exchange rate volatility effect is positive - a result in accordance with the assertion that high ex post exchange rate volatility can lead to large uncovered interest and relative purchasing power differentials.

Unlike exchange rate volatility, the other policy variable - relative inflation volatility $M V P_{j, t}$, has very limited effect on the differential series under investigation. Indeed, for all the three differential series, the estimates of the $M V P_{j, t}$ coefficient are both small and statistically insignificant. Since the exchange rate is more volatile than inflation in several cases, the relatively low variability of inflation may contribute to the lack of significant results.

Overall, the ability of the selected economic variables to explain the behavior of deviations from parities is mixed. ${ }^{23}$ While they explain about one third of the variations in absolute uncovered interest and absolute relative purchasing power parity differentials, they offer little help in explaining movements in absolute real interest differentials. The trade variable tends to have the wrong sign and the relative inflation variance variable is not significant. On the other hand, the capital controls, FDI, and exchange rate volatility variables have the expected sign when they are significant. Thus, given the exploratory nature of the exercise, the results are quite encouraging.

23 We also considered samples consist of observations from only Hong Kong/PRC and Taiwan/PRC and from only Japan/PRC and US/PRC. The regression results are qualitatively the same as those reported. 


\section{Concluding Remarks}

The integration of the PRC into the world economy has preoccupied business leaders and policy makers alike. There is a plethora of evidence that flows of capital and goods to and from the PRC are increasing rapidly. This study has undertaken a price-based (prices of goods, prices of assets) assessment of the degree of integration. We consider three parity conditions, based on economic theory. They include real interest parity as an indicator of "real" capital mobility, uncovered interest parities for assessing financial capital mobility, and deviations from relative purchasing power parity for measuring goods market integration. We find, to varying degrees, that the long-run version of the three parity conditions hold between the PRC and the other Greater China economies as well as its major trading partner - Japan and the US. On the other hand, the data do not in general satisfy the short-run parity conditions and we can conclude that the markets are not completely efficient.

In comparing the levels of integration between the PRC and the two other Greater China economies (Hong Kong and Taiwan) and the two other non-Greater China economies (Japan and the US), there is no substantial evidence that the integration among the Greater China economies is stronger than that between the PRC and the non-Greater China economies. In general, Hong Kong appears to have an advanced level of integration with the PRC. On the other hand, the PRC's link with Taiwan, another Greater China economy, is no stronger than those with Japan and the US. The contrasting results for Hong Kong and Taiwan suggest that, during the sample period, integration with the PRC is not necessary an intrinsic characteristics of a Greater China economy. In addition, we observe that the exchange rate regime choice has substantial implications for the results regarding financial and goods market integration. A de facto fixed exchange rate arrangement is associated with strong evidence of integration while weak integration tends to occur with a flexible rate arrangement. A similar finding does not apply to the composite integration criterion corresponding to real interest parity. We conjecture that this is because the large expectational errors associated with floating exchange rates do not directly enter into this parity condition.

Even though the statistical results offer some evidence of integration, we recognize that there are non-negligible restrictions on both physical and financial flows between the PRC and other economies. Recent developments are, however, quite promising. For instance, the PRC's current efforts to promote trade with other East Asian economies and scheduled removal of trade 
barriers associated with joining the WTO suggest that the process of integrating the PRC into the world economy will continue.

One interesting aspect of this study is that we not only find increasing convergence in the three parities, we also empirically identify several regulatory and economic policy factors that determine the process of convergence. Specifically, proxies for capital controls, trade intensity, FDI, and exchange rate volatility are found to be significant factors though the trade intensity variable has the wrong sign. The results are quite positive given the exiguity of quality data on these regulatory and administrative variables. Nonetheless, we believe that additional analyses using different criteria of integration and alternative measures of regulatory and economic policy factors can offer valuable and complementary insights on integration between the PRC and other economies. $^{24}$

We also confirm results found elsewhere in the international finance literature - namely that deviations from parity conditions depend upon the regime. When the exchange rate is effectively pegged, then the variability of the shocks to relative purchasing power parity is on the same order as those to real interest parity. In contrast, when exchange rates are (managed) floating, the shocks to relative purchasing power parity are on the same order as those to uncovered interest parity. This suggests that the size of the relative purchasing power parity perturbations is a function of the exchange rate regime the PRC has maintained since 1994. As the PRC moves toward currency convertibility, it is likely that over the intermediate run, some form of managed float will likely be implemented. The variability of the deviations from relative PPP, and hence real interest parity, will likely depend on how the PRC manages its macroeconomy, and in particular, how it deals with the contingent liabilities of the banking sector and the pension system.

$24 \quad$ The concept of integration is difficult to define and measure precisely. Other approaches to assess integration include a) measuring trade linkages, b) comparing the expected yields on similar assets in different economies, and c) evaluating the correlation of (output) shocks across economies and the relative contributions of common and economy-specific shocks to output variations. 


\section{Data Appendix}

The interest rate and price data are collected from four sources - Bloomberg Financial Services, CEIC database, International Financial Statistics, and the Hong Kong Monetary Authority. The monthly series retrieved from Bloomberg is the PRC one-month interbank offer rate. The monthly series retrieved from CEIC are the Hong Kong one-month interbank offer rate, the Taiwan one-month interbank offer rate, the Taiwan-US exchange rate, the Hong Kong consumer price index, and the Taiwan consumer price index. The Taiwan interest rate is the middle rate given by a simple average of the high and low rates. The monthly series from International Financial Statistics are dollar-based exchange rates of Hong Kong dollar and China yuan. The Hong Kong Monetary Authority provided the PRC consumer price series.

The sample period is from February 1996 to June 2002. The X-12 routine (with multiplicative factors on the levels) was used to seasonally adjust all the price series. The Japanese CPI series also had an adjustment for the imposition of new taxes in April 1997.

In section 4, the capital control data were obtained from James Chan-Lee, and are described in Chan-Lee (2002). These indices were tabulated using the criteria and methodology of Quinn (1997); the recorded degree of restrictiveness is based on a reading of the regulations in place. Higher values indicate less restrictiveness. Values for 2001 were assumed to equal the 2000 values for all cases except Taiwan, which uses the preliminary value assigned. In constructing the trade variable, the data on imports and exports are extracted from the Direction of Trade Statistics for all economies but Taiwan. The Taiwan data are provided by the Board of Foreign Trade of Taiwan at their website. The FDI data are obtained from the CEIC database. The 13-month centered moving variances of exchange rate changes and inflations rates are calculated using the consumer price and exchange rate data described above. 


\section{References}

Campa, Jose M. and Holger C. Wolf, 1997, “Is Real Exchange Rate Mean Reversion Caused By Arbitrage?” NBER Working Paper \#6162.

Chan-Lee, James, 2002, "Beyond Sequencing: What does a risk-based analysis of core institutions, domestic financial and capital account liberalization reveal about systemic risk in Asian Emerging Market Economies?” ADBI Research Paper No.46 (Asian Development Bank Institute, November).

Cheung, Yin-Wong, Menzie Chinn and Eiji Fujii, 2003, “China, Hong Kong and Taiwan: Real and Financial Integration," CESifo Working Paper \#851; forthcoming, China Economic Review.

Chinn, Menzie and Jeffrey Frankel, 1994, "Financial Links around the Pacific Rim: 1982-1992," in R. Glick and M. Hutchison (editors), Exchange Rate Policy and Interdependence: Perspective from the Pacific Basin (Cambridge: Cambridge University Press): 17-26.

The Economist Intelligence Unit, 2003, Country Report March 2003 - China, (London, UK: The Economist Intelligence Unit Limited)

Cumby, Robert E. and Frederick S. Mishkin, 1986, “The International Linkage of Real Interest Rates: The European-U.S. Connection," Journal of International Money and Finance 5: $5-23$.

Cumby, Robert E. and Maurice Obstfeld, 1984, "International Interest Rate and Price Level Linkages under Flexible Exchange Rates: A Review of Recent Evidence,” in J. F. O. Bilson and R. C. Marston (editors) Exchange rate Theory and Practice (University of Chicago Press, Chicago, IL): 121-151.

Elliott, Graham, Thomas J. Rothenberg, and James H. Stock, 1996, “Efficient Tests for an Autoregressive Unit Root," Econometrica, 64: 813-836.

Fernald, John, Hali Edison, and Prakash Loungani, 1999, "Was China the First Domino? Assessing Links between China and Other Asian Economies," Journal of International Money and Finance 18: 515-535.

Frankel, Jeffrey A., 1991, "Quantifying International Capital Mobility,” in D. Bernheim and J. Shoven (editors), National Saving and Economic Performance (Chicago: University of Chicago Press): 227-260. 
Frankel, Jeffrey A. and Kenneth A. Froot, 1997, “Using Survey Data to Test Standard Propositions Regarding Exchange Rate Expectations, American Economic Review 77, $133-153$.

Frankel, Jeffrey A. and Andrew Rose, 1998, "The Endogeneity of the Optimum Currency Area Criteria," Economic Journal 108, 1009-1025.

Goldberg, Linda S. and Michael W. Klein, 1998, "Foreign Direct Investment, Trade and Real Exchange Rate Linkages in Developing Countries," in G. Reuven (editor) Managing Capital Flows and Exchange Rates: Perspectives from the Pacific Basin (Cambridge: Cambridge University Press): 73-100.

Goldberg, Linda S. and Michael W. Klein, 1999, "International Trade and Factor Mobility: An Empirical Investigation,” NBER Working Paper \#7196.

Ha, Jiming, and Kelvin Fan, 2002, "Price Convergence Between Hong Kong and the Mainland," Research Memorandum, Hong Kong Monetary Authority.

Harding, Harry, 1995, “The Concept of 'Greater China': Themes, Variations and Reservations' in Shambaugh, Davis (ed), Greater China: The Next Superpower? Oxford: Clarendon, pp. 8-34.

Li, Yang and Xingyun Peng, 2002, "The Money Market in China: Theory and Practice," China and the World Economy 10: 3-10.

Ma, Jun, 2001, “Quantifying the Effect of China's WTO Entry," Global Markets Research (Hong Kong: DeutscheBank, December).

Mark, Nelson, 1985, "Some Evidence on the International Inequality of Real Interest Rates," Journal of International Money and Finance 4: 189-208.

Mishkin, Frederick S., 1984, “Are Real Interest Rates Equal Across Countries? An Empirical Investigation of International Parity Conditions," Journal of Finance 39: 1345-1357.

Naughton, Barry (ed.), 1997, China Circle: Economics \& Technology in the PRC, Taiwan, \& Hong Kong, (Washington, DC: Brookings Institution).

Noland, Marcus, LiGang Liu, Sherman Robinson, and Zhi Wang, 1998, Global Economic Effects of the Asian Currency Devaluations, Policy Analyses in International Economics 56 (Washington, D.C.: Institute for International Economics).

Quinn, Dennis, 1997, “The correlates of change in international financial regulation," American Political Science Review 91(3): 531-551. 
Roll, Richard, 1979, "Violations of Purchasing Power Parity and their Implications for Efficient International Commodity Markets," in M. Sarnat and G.P. Szego (editors), International Finance and Trade (Ballinger Publishing: Cambridge, MA.): 133-176.

Shellekens, Philip, 2002, "Deflation in Hong Kong, SAR,” People's Republic of China - Hong Kong Special Administrative Region: Selected Issues, IMF Country Report 02/99 (IMF: Washington, DC, May).

Wang, Zhi, 2001, “The Impact of China's WTO Accession on Patterns of World Trade," Paper presented at ASSA Annual Meeting in Atlanta Georgia, January 4-6, 2002.

Wei, Shang-Jin, and Jeffrey Frankel, 1994, “A ‘Greater China’ Trade Bloc?” China Economic Review 5: 179-190.

Wei, Shang-Jin, Ligang Liu, Zhi Wang and Wing T. Woo, 2000, “The China Money Puzzle: Will Devaluation of the Yuan Help or Hurt the Hong Kong Dollar? China Economic Review 11: 171-188.

Willett, Thomas D, Manfred W. Keil and Young-Seok Ahn, 2002, "Capital Mobility for Developing Countries May Not Be So High,” Journal of Development Economics 68(2): 421-34.

Xie, Duo, 2002, "Analysis of the Development of China's Money Market," China and the World Economy 10: 29-37 
Table 1. Descriptive Statistics

\begin{tabular}{lcccc}
\hline & Hong Kong/PRC & Taiwan/PRC & US/PRC & Japan/PRC \\
\hline A. Real interest differentials & & & \\
Mean & -0.178 & -1.847 & $-3.245^{* *}$ & $-5.289^{* *}$ \\
Maximum & 21.260 & 19.427 & 11.056 & 8.363 \\
Minimum & -20.899 & -43.994 & -20.383 & -16.633 \\
Variance & 86.818 & 114.100 & 41.161 & 40.912 \\
B. Uncovered interest differentials & & & \\
Mean & $-1.276^{* *}$ & $-7.274^{*}$ & $-1.718^{* *}$ & $-17.382^{* *}$ \\
Maximum & 9.787 & 51.813 & 4.434 & 79.034 \\
Minimum & -9.150 & -160.383 & -8.377 & -128.787 \\
Variance & 14.349 & 714.270 & 13.964 & 1744.785 \\
C. Deviations from relative purchasing power parity & & & \\
Mean & 1.097 & $5.426^{\#}$ & $-1.527^{*}$ & $12.092^{*}$ \\
Maximum & 22.701 & 166.622 & 14.797 & 130.708 \\
Minimum & -16.187 & -62.297 & -18.703 & -87.654 \\
Variance & 57.931 & 782.878 & 37.988 & 1788.675 \\
\hline
\end{tabular}

Notes: The real interest differentials, uncovered interest differentials, and deviations from relative purchasing power parity are all annualized and measured in percentage terms. The economy-pairs are labeled in the first row. "**," "**," and " "\#" indicate that the sample mean is significantly different from zero at the 1,5 , and $10 \%$ levels, respectively. 
Table 2. Real Interest Differentials

\begin{tabular}{|c|c|c|c|c|}
\hline & Hong Kong/PRC & Taiwan/PRC & $\mathrm{US} / \mathrm{PRC}$ & Japan/PRC \\
\hline \multicolumn{5}{|c|}{ A. Unit root test satistics } \\
\hline ADF-GLS $\mu$ & $-3.626^{*}[3]$ & $-2.358 *[6]$ & $-3.195 *[4]$ & $-2.436^{*}[4]$ \\
\hline $\mathrm{Q}(6)$ & 10.067 & 0.642 & 0.385 & 0.957 \\
\hline $\mathrm{Q}(12)$ & 17.192 & 3.967 & 16.055 & 10.715 \\
\hline ADF-GLS $\tau$ & $-7.187 *[1]$ & $-4.996 *[5]$ & $-6.684 *[1]$ & $-7.145 *[1]$ \\
\hline $\mathrm{Q}(6)$ & 8.442 & 10.574 & 5.402 & 6.532 \\
\hline $\mathrm{Q}(12)$ & 13.866 & 15.265 & 16.088 & 13.956 \\
\hline \multicolumn{5}{|l|}{ B. Persistence } \\
\hline $\operatorname{AR}(1)$ & $\begin{array}{l}0.270^{*} \\
(0.120)\end{array}$ & $\begin{array}{c}-0.231^{*} \\
(0.107)\end{array}$ & $\begin{array}{l}0.241^{*} \\
(0.121)\end{array}$ & $\begin{array}{c}0.168 \\
(0.117)\end{array}$ \\
\hline $\operatorname{AR}(2)$ & $\begin{array}{l}0.250^{*} \\
(0.121)\end{array}$ & $\begin{array}{l}-0.175 \\
(0.111)\end{array}$ & $\begin{array}{l}-0.118 \\
(0.125)\end{array}$ & $\begin{array}{c}0.080 \\
(0.120)\end{array}$ \\
\hline $\operatorname{AR}(3)$ & $\begin{array}{l}-0.063 \\
(0.120)\end{array}$ & $\begin{array}{c}-0.053 \\
(0.113)\end{array}$ & $\begin{array}{c}0.068 \\
(0.126)\end{array}$ & $\begin{array}{c}0.035 \\
(0.120)\end{array}$ \\
\hline $\operatorname{AR}(4)$ & - & $\begin{array}{l}-0.001 \\
(0.113)\end{array}$ & $\begin{array}{c}0.171 \\
(0.125)\end{array}$ & $\begin{array}{l}0.285^{*} \\
(0.120)\end{array}$ \\
\hline $\operatorname{AR}(5)$ & - & $\begin{array}{c}0.136 \\
(0.111)\end{array}$ & - & - \\
\hline $\operatorname{AR}(6)$ & - & $\begin{array}{c}0.420^{* *} \\
(0.108)\end{array}$ & - & - \\
\hline Adjusted $\mathrm{R}^{2}$ & 0.124 & 0.192 & 0.045 & 0.103 \\
\hline \multicolumn{5}{|c|}{ C. Trends in annual absolute averages } \\
\hline Individual & $\begin{array}{l}-0.484^{\#} \\
(0.208)\end{array}$ & $\begin{array}{l}-0.471 \\
(0.283)\end{array}$ & $\begin{array}{l}-0.277 \\
(0.166)\end{array}$ & $\begin{array}{l}-0.961 * \\
(0.334)\end{array}$ \\
\hline Group & \multicolumn{2}{|c|}{$\begin{array}{c}-0.478^{*} \\
(0.162)\end{array}$} & \multirow{2}{*}{\multicolumn{2}{|c|}{$\begin{array}{c}-0.619 * \\
(0.219)\end{array}$}} \\
\hline Common & & & & \\
\hline
\end{tabular}

Notes: Results on the properties of real interest differentials are presented. The economy-pairs are labeled in the first row. Panel A gives the ADF-GLS ${ }^{\tau}$ and ADF-GLS ${ }^{\mu}$ unit root test results. Levels of significance are determined using finite sample critical values (Cheung and Lai, 1995). Figures in square brackets are lag parameters selected by the Bayesian information criterion. Q(6) and Q(12) are the Box-Ljung Q-statistics based on the first six and twelve autocorrelations of the estimated residuals. Panel B gives the persistence of real interest differentials estimated from equation (9). Panel C gives the common and economy-pair (individual) specific trend estimates of the annual average of absolute real interest differentials (equation (11)). Robust standard errors are reported in parentheses underneath coefficient estimates. Significance at the 1,5 and 10\% levels are indicated by “**," "*," and “\#," respectively. 
Table 3. Uncovered Interest Differentials

\begin{tabular}{|c|c|c|c|c|}
\hline 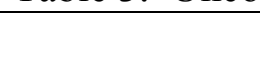 & Hong Kong/PRC & Taiwan/PRC & US/PRC & Japan/PRC \\
\hline \multicolumn{5}{|c|}{ A. Unit root test statistics } \\
\hline ADF-GLS $\mu$ & $-2.126 *[5]$ & $-7.019 *[1]$ & $-1.698[3]$ & $-8.344 *[1]$ \\
\hline $\mathrm{Q}(6)$ & 5.554 & 10.304 & 3.748 & 6.429 \\
\hline $\mathrm{Q}(12)$ & 10.670 & 18.275 & 14.363 & 14.396 \\
\hline ADF-GLS $\tau$ & $-2.808^{\#}[2]$ & $-4.892 *[2]$ & $-1.263[3]$ & $-8.794 *[1]$ \\
\hline $\mathrm{Q}(6)$ & 9.457 & 8.471 & 3.534 & 6.648 \\
\hline $\mathrm{Q}(12)$ & 17.473 & 18.375 & 14.266 & 12.773 \\
\hline \multicolumn{5}{|l|}{ B. Persistence } \\
\hline $\mathrm{AR}(1)$ & $\begin{array}{l}0.429^{* *} \\
(0.118)\end{array}$ & $\begin{array}{c}0.189 \\
(0.115)\end{array}$ & $\begin{array}{c}0.384^{* *} \\
(0.115)\end{array}$ & $\begin{array}{l}-0.022 \\
(0.118)\end{array}$ \\
\hline $\operatorname{AR}(2)$ & $\begin{array}{c}0.137 \\
(0.129)\end{array}$ & - & $\begin{array}{l}0.268^{*} \\
(0.119)\end{array}$ & - \\
\hline $\operatorname{AR}(3)$ & $\begin{array}{c}0.070 \\
(0.130)\end{array}$ & - & $\begin{array}{l}0.270^{*} \\
(0.112)\end{array}$ & - \\
\hline $\operatorname{AR}(4)$ & $\begin{array}{l}-0.073 \\
(0.129)\end{array}$ & - & - & - \\
\hline $\operatorname{AR}(5)$ & $\begin{array}{l}0.282^{*} \\
(0.115)\end{array}$ & - & - & - \\
\hline Adjusted $\mathrm{R}^{2}$ & 0.620 & 0.022 & 0.829 & -0.013 \\
\hline \multicolumn{5}{|c|}{ C. Trends in annual absolute averages } \\
\hline Individual & $\begin{array}{c}-0.950^{*} \\
(0.299)\end{array}$ & $\begin{array}{l}-1.760 \\
(2.448)\end{array}$ & $\begin{array}{l}-1.005^{*} \\
(0.282)\end{array}$ & $\begin{array}{l}-0.429 \\
(1.902)\end{array}$ \\
\hline Group & \multicolumn{2}{|c|}{$\begin{array}{l}-1.355 \\
(1.292)\end{array}$} & \multirow{2}{*}{\multicolumn{2}{|c|}{$\begin{array}{l}-0.717 \\
(0.790)\end{array}$}} \\
\hline Common & & & & \\
\hline
\end{tabular}

Notes: Results on the properties of uncovered interest differentials are presented. The economypairs are labeled in the first row. Panel A gives the ADF-GLS ${ }^{\tau}$ and ADF-GLS ${ }^{\mu}$ unit root test results. Levels of significance are determined using finite sample critical values (Cheung and Lai, 1995). Figures in square brackets are lag parameters selected by the Bayesian information criterion. Q(6) and $\mathrm{Q}(12)$ are the Box-Ljung Q-statistics based on the first six and twelve autocorrelations of the estimated residuals. Panel B gives the persistence of real interest differentials estimated from equation (9). Panel $\mathrm{C}$ gives the common and economy-pair (individual) specific trend estimates of the annual average of absolute real interest differentials (equation (11)). Robust standard errors are reported in parentheses underneath coefficient estimates. Significance at the 1,5 and 10\% levels are indicated by “**," "“*," and “\#,” respectively. 
Table 4. Deviations from Relative Purchasing Power Parity

\begin{tabular}{|c|c|c|c|c|}
\hline & Hong Kong/PRC & Taiwan/PRC & $\mathrm{US} / \mathrm{PRC}$ & Japan/PRC \\
\hline \multicolumn{5}{|c|}{ A. Unit root test statistics } \\
\hline ADF-GLS $\mu$ & $-7.802 *[1]$ & $-7.568 *[1]$ & $-2.173 *[4]$ & $-3.291 *[3]$ \\
\hline $\mathrm{Q}(6)$ & 10.144 & 4.479 & 1.126 & 3.897 \\
\hline $\mathrm{Q}(12)$ & 14.180 & 17.802 & 18.415 & 12.809 \\
\hline ADF-GLS $\tau$ & $-8.025 *[1]$ & $-4.069 *[4]$ & $-2.810^{\#}[6]$ & $-8.602 *[1]$ \\
\hline $\mathrm{Q}(6)$ & 7.455 & 0.868 & 0.421 & 5.737 \\
\hline $\mathrm{Q}(12)$ & 9.574 & 15.862 & 17.863 & 13.984 \\
\hline \multicolumn{5}{|l|}{ B. Persistence } \\
\hline $\operatorname{AR}(1)$ & $\begin{array}{c}0.094 \\
(0.116)\end{array}$ & $\begin{array}{c}0.115 \\
(0.116)\end{array}$ & $\begin{array}{c}0.123 \\
(0.118)\end{array}$ & $\begin{array}{c}-0.046 \\
(0.120)\end{array}$ \\
\hline $\operatorname{AR}(2)$ & - & - & $\begin{array}{l}-0.209^{\#} \\
(0.114)\end{array}$ & $\begin{array}{l}-0.102 \\
(0.121)\end{array}$ \\
\hline $\operatorname{AR}(3)$ & - & - & $\begin{array}{c}0.031 \\
(0.116)\end{array}$ & $\begin{array}{c}0.118 \\
(0.121)\end{array}$ \\
\hline $\operatorname{AR}(4)$ & - & - & $\begin{array}{c}0.175 \\
(0.116)\end{array}$ & - \\
\hline Adjusted $\mathrm{R}^{2}$ & -0.004 & -0.002 & 0.043 & -0.013 \\
\hline \multicolumn{5}{|c|}{ C. Trends in annual absolute averages } \\
\hline Individual & $\begin{array}{c}0.025 \\
(0.160)\end{array}$ & $\begin{array}{c}-1.199 \\
(1.838)\end{array}$ & $\begin{array}{c}0.264 \\
(0.222)\end{array}$ & $\begin{array}{c}0.775 \\
(1.580)\end{array}$ \\
\hline Group & \multicolumn{2}{|c|}{$\begin{array}{c}-0.586 \\
(0.914)\end{array}$} & \multirow{2}{*}{\multicolumn{2}{|c|}{$\begin{array}{c}0.519 \\
(0.672)\end{array}$}} \\
\hline Common & & & & \\
\hline
\end{tabular}

Notes: Results on the properties of relative purchasing power parity differentials are presented. The economy-pairs are labeled in the first row. Panel A gives the ADF-GLS ${ }^{\tau}$ and ADF-GLS ${ }^{\mu}$ unit root test results. Levels of significance are determined using finite sample critical values (Cheung and Lai, 1995). Figures in square brackets are lag parameters selected by the Bayesian information criterion. Q(6) and Q(12) are the Box-Ljung Q-statistics based on the first six and twelve autocorrelations of the estimated residuals. Panel B gives the persistence of real interest differentials estimated from equation (9). Panel $\mathrm{C}$ gives the common and economy-pair (individual) specific trend estimates of the annual average of absolute real interest differentials (equation (11)). Robust standard errors are reported in parentheses underneath coefficient estimates. Significance at the 1, 5 and $10 \%$ levels are indicated by “**," “*," and "\#," respectively. 
Table 5. Summary of the Parity Conditions

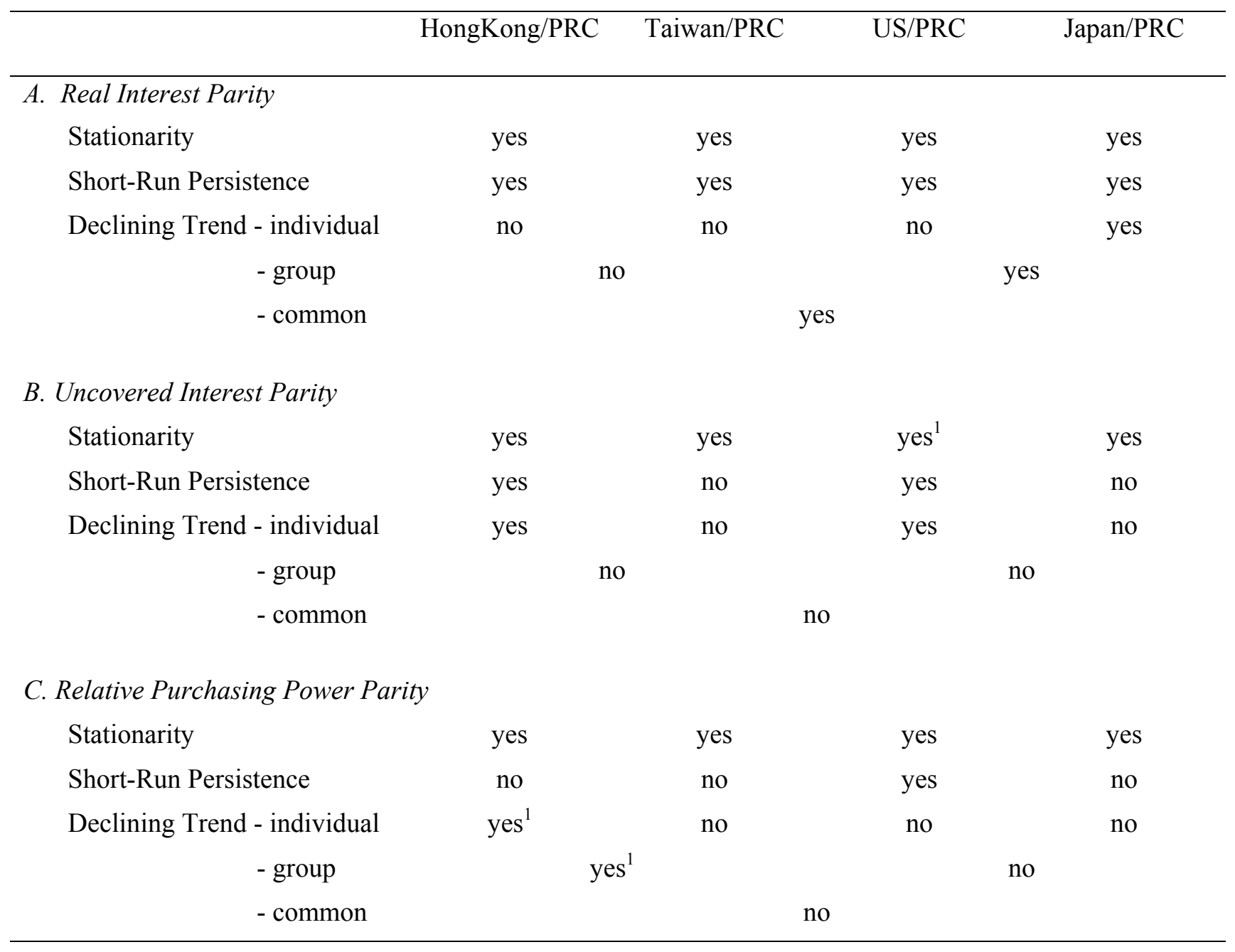

Note: The table summarizes the test results reported in Tables 2, 3, and 4. The rows labeled "Stationarity," "Short-Run Persistence," and "Declining Trend" correspond to the "Unit root test statistics," "Persistence," and "Trends in absolute annual averages" presented in the preceding tables.

1. The result allowing for the 1997 dummy variable as discussed in the text.

2. The result based on the extended sample discussed in the text. 
Table 6. Decomposition of Parity Differential Variances

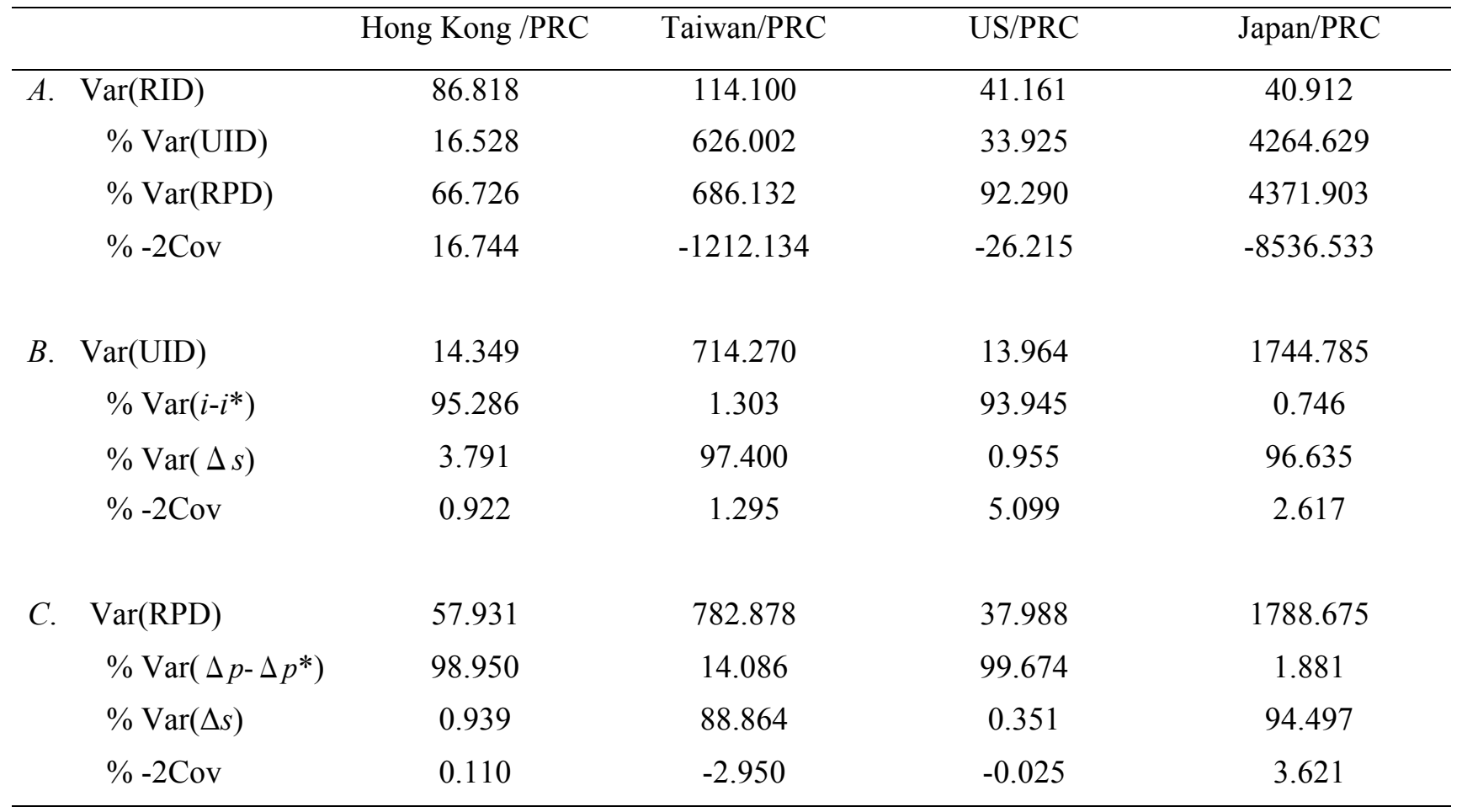

Notes: The economy-pairs are labeled in the first row. Panel A gives the variance of real interest differentials and its components according to

$\operatorname{Var}\left(r_{t, k}-r_{t, k}^{*}\right) \equiv \operatorname{Var}\left(i_{t, k}-i_{t, k}^{*}-\Delta s_{t, k}\right)+\operatorname{Var}\left(\pi_{t, k}-\pi_{t, k}^{*}-\Delta s_{t, k}\right)$

$-2 \operatorname{Cov}\left(i_{t, k}-i_{t, k}^{*}-\Delta s_{t, k}, \pi_{t, k}-\pi_{t, k}^{*}-\Delta s_{t, k}\right)$.

"Var(RID)" gives $\operatorname{Var}\left(r_{t, k}-r_{t, k}^{*}\right)$, “\% $\operatorname{Var}(\mathrm{UID})$ )" gives the percentage contribution of $\operatorname{Var}\left(i_{t, k}-i_{t, k}^{*}-\Delta s_{t, k}\right), “ \% \operatorname{Var}(\mathrm{RPD})$ " gives the percentage contribution of $\operatorname{Var}\left(\pi_{t, k}-\pi_{t, k}^{*}-\Delta s_{t, k}\right)$, and " $\%-2 \mathrm{Cov"} \mathrm{gives} \mathrm{the} \mathrm{percentage} \mathrm{contribution} \mathrm{of} \mathrm{the} \mathrm{covariance} \mathrm{term.}$

Panel B gives the variance of real interest differentials and its components according to $\operatorname{Var}\left(i_{t, k}-i_{t, k}^{*}-\Delta s_{t, k}\right) \equiv \operatorname{Var}\left(i_{t, k}-i_{t, k}^{*}\right)+\operatorname{Var}\left(\Delta s_{t, k}\right)-2 \operatorname{Cov}\left(i_{t, k}-i_{t, k}^{*}, \Delta s_{t, k}\right) \cdot$ "Var(UID)" gives $\operatorname{Var}\left(i_{t, k}-i_{t, k}^{*}-\Delta s_{t, k}\right), “ \% \operatorname{Var}\left(i-i^{*}\right)$ " gives the percentage contribution of $\operatorname{Var}\left(i_{t, k}-i_{t, k}^{*}\right), “ \% \operatorname{Var}(\Delta$ $s)$ " gives the percentage contribution of $\operatorname{Var}\left(\Delta s_{t, k}\right)$, and “\% -2Cov" gives the percentage contribution of the covariance term.

Panel $\mathrm{C}$ gives the variance of relative purchasing power parity differentials and its components according to $\operatorname{Var}\left(\pi_{t, k}-\pi_{t, k}^{*}-\Delta s_{t, k}\right) \equiv \operatorname{Var}\left(\pi_{t, k}-\pi_{t, k}^{*}\right)+\operatorname{Var}\left(\Delta s_{t, k}\right)$ $-2 \operatorname{Cov}\left(\pi_{t, k}-\pi_{t, k}^{*}, \Delta s_{t, k}\right)$. "Var(RPD)" gives $\operatorname{Var}\left(\pi_{t, k}-\pi_{t, k}^{*}-\Delta s_{t, k}\right), “ \% \operatorname{Var}\left(\Delta p-\Delta p^{*}\right)$ " gives the percentage contribution of $\operatorname{Var}\left(\pi_{t, k}-\pi_{t, k}^{*}\right)$, “\% $\operatorname{Var}(\Delta s)$ " gives the percentage contribution of $\operatorname{Var}\left(\Delta s_{t, k}\right)$, and " $\%-2 \operatorname{Cov"~gives~the~percentage~contribution~of~the~covariance~term.~}$ 
Table 7. Panel Regression Results on the Absolute Deviations from the Parity Conditions

Dependent Variable

\begin{tabular}{|c|c|c|c|}
\hline & $\begin{array}{l}\text { Absolute Real Interest } \\
\text { Differentials }\end{array}$ & $\begin{array}{l}\text { Absolute Uncovered } \\
\text { Interest Differentials }\end{array}$ & $\begin{array}{c}\text { Absolute Relative } \\
\text { Purchasing Power } \\
\text { Differentials }\end{array}$ \\
\hline KAOPEN $_{j, t}$ & $\begin{array}{l}-1.062 \\
(1.267)\end{array}$ & $\begin{array}{l}-6.378^{\#} \\
(3.283)\end{array}$ & $\begin{array}{l}-6.579^{*} \\
(3.242)\end{array}$ \\
\hline$T R A D E_{j, t}$ & $\begin{array}{c}0.496 \\
(0.815)\end{array}$ & $\begin{array}{c}5.718 \\
(3.928)\end{array}$ & $\begin{array}{l}7.988^{*} \\
(3.854)\end{array}$ \\
\hline$F D I_{j, t}$ & $\begin{array}{c}0.709 \\
(0.480)\end{array}$ & $\begin{array}{l}-3.046^{\#} \\
(1.553)\end{array}$ & $\begin{array}{l}-3.363^{*} \\
(1.492)\end{array}$ \\
\hline$M V S_{j, t}$ & $\begin{array}{c}0.000 \\
(0.000)\end{array}$ & $\begin{array}{l}0.013 * * \\
(0.002)\end{array}$ & $\begin{array}{l}0.011 * * \\
(0.002)\end{array}$ \\
\hline$M V P_{j, t}$ & $\begin{array}{c}0.020 \\
(0.022)\end{array}$ & $\begin{array}{l}-0.008 \\
(0.027)\end{array}$ & $\begin{array}{c}0.050 \\
(0.031)\end{array}$ \\
\hline Constant & $\begin{array}{l}15.533 \\
(7.948)\end{array}$ & $\begin{array}{l}30.555 \\
(20.218)\end{array}$ & $\begin{array}{l}36.198 \\
(20.225)\end{array}$ \\
\hline Adjusted $\mathrm{R}^{2}$ & 0.024 & 0.368 & 0.331 \\
\hline
\end{tabular}

Notes: Absolute deviations from real interest parity, uncovered interest parity, and relative purchasing power parity are regressed on the variables listed in the first column using panel data with $j=$ Hong Kong, Taiwan, the U.S., and Japan. Heteroskedasticity-consistent standard errors are provided in the parentheses. "**," "**," and " *\#" indicate statistical significance at the 1,5 , and $10 \%$ levels, respectively. 
Figure 1. Deviations from the parity conditions between Hong Kong and PRC

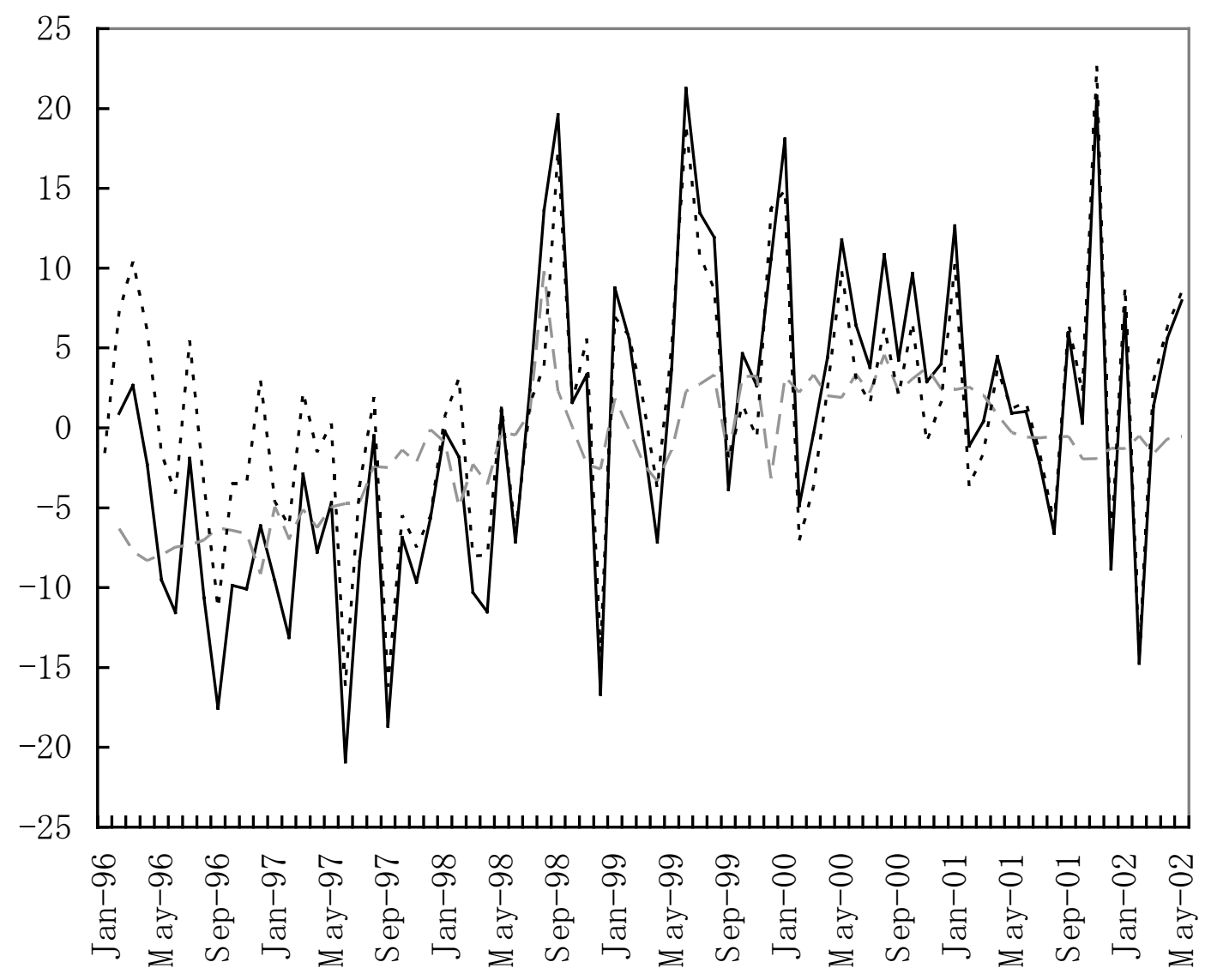

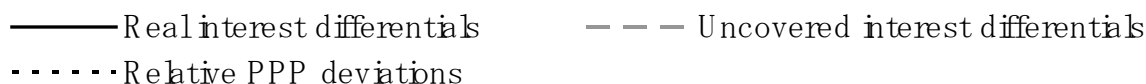


Figure 2. Deviations from the parity conditions between Taiwan and PRC

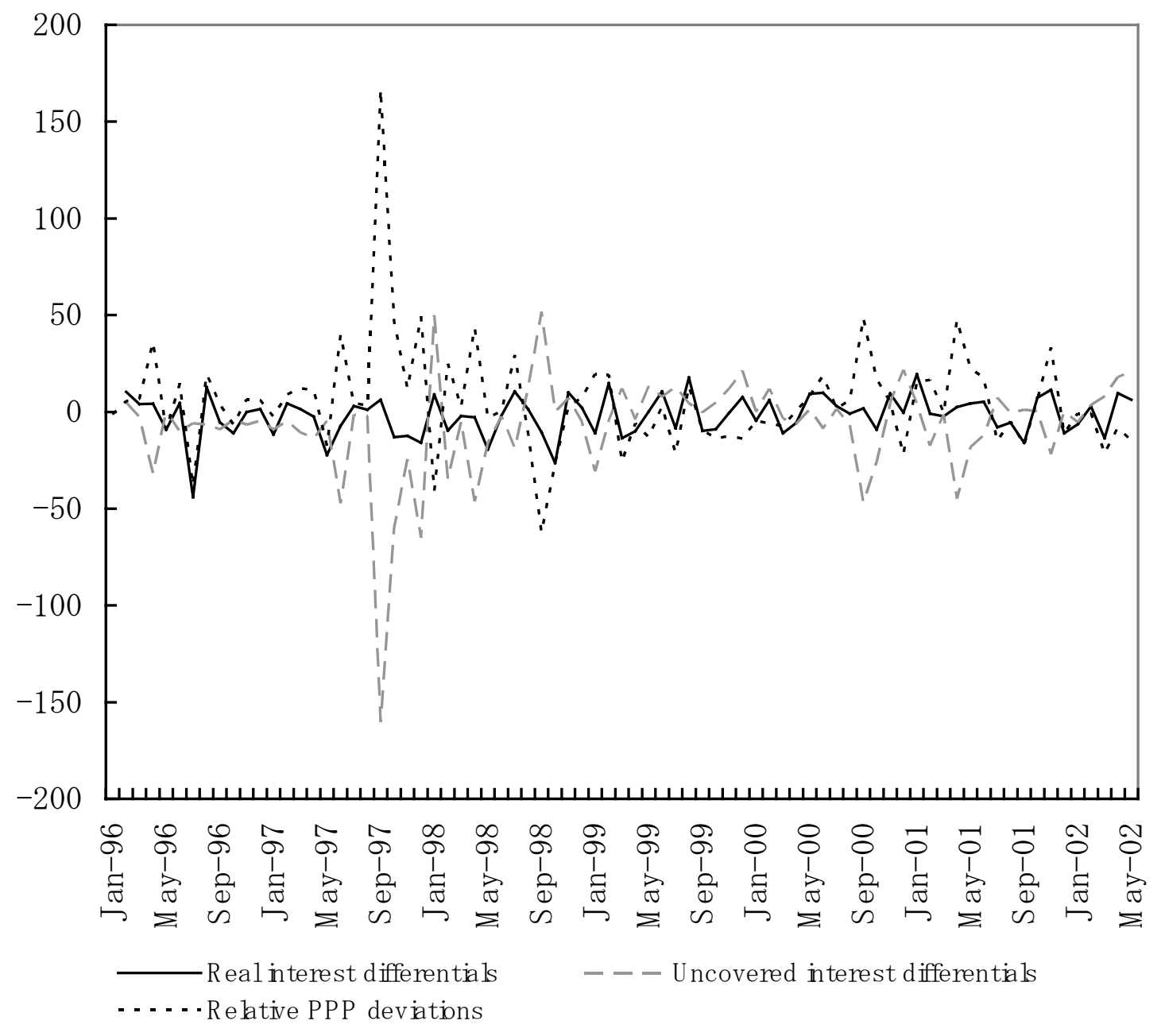


Figure 3. Deviations from the parity conditions between U.S. and PRC

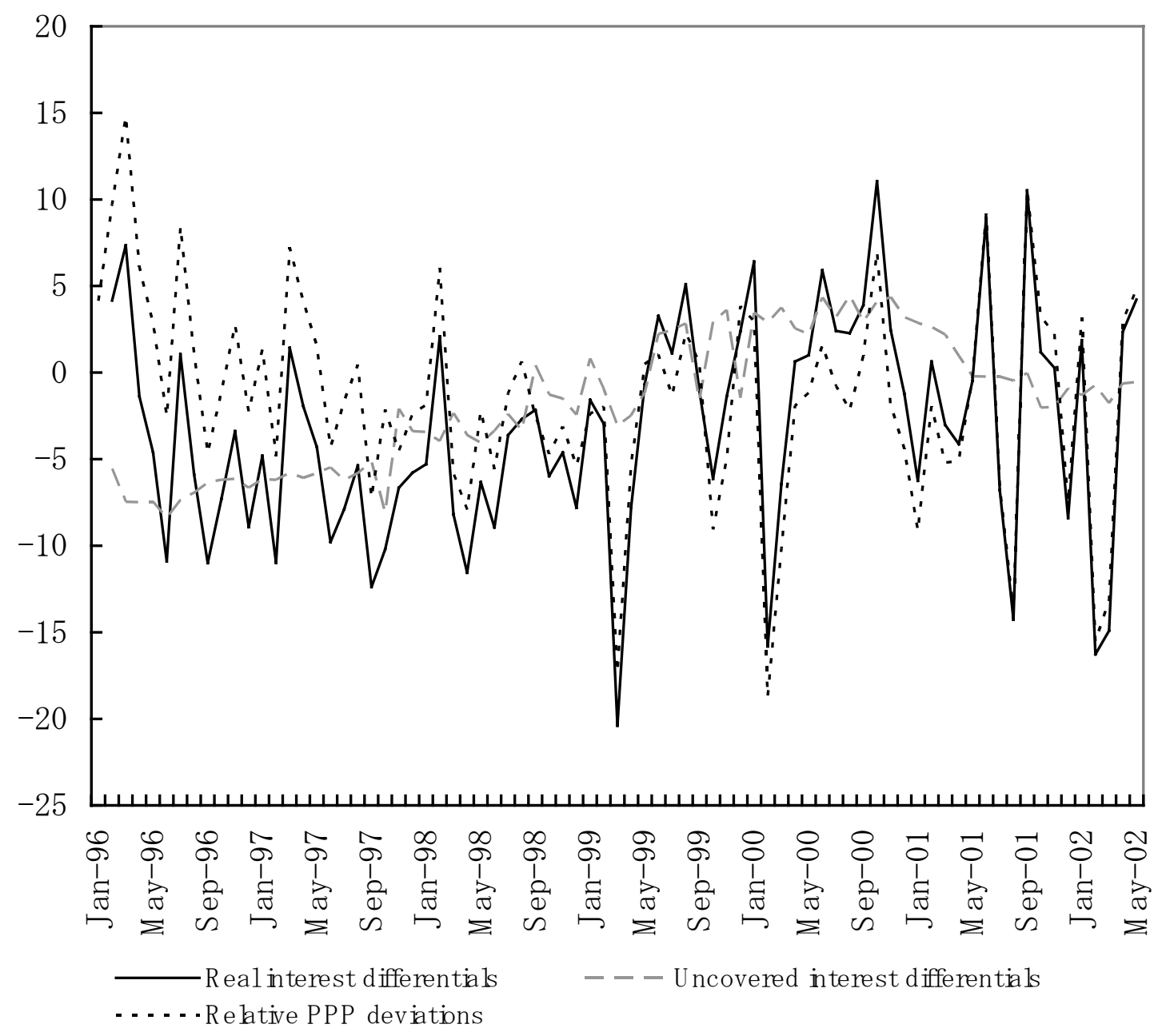


Figure 4. Deviations from the parity conditions between Japan and PRC

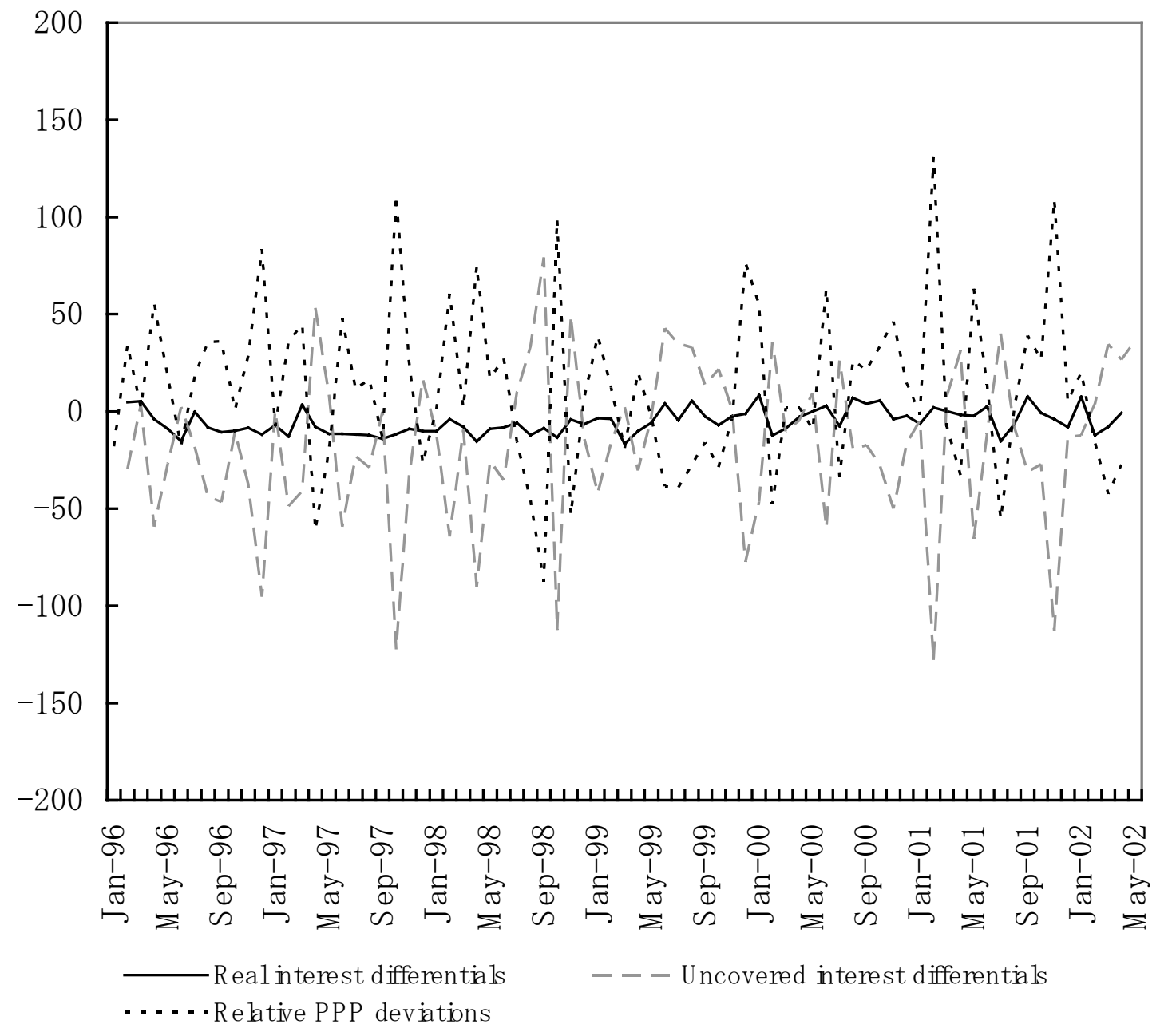

